\title{
CRIANÇAS E ADOLESCENTES NO BRASIL: A POTÊNCIA FRATERNA DA PROTEÇÃO INTEGRAL FRENTE À PANDEMIA PELA DISSEMINAÇÃO DO CORONAVÍRUS DE 2020
}

\author{
Danielle M. Espezim dos Santos ${ }^{1}$ \\ DOI: https://doi.org/10.47306/978-65-88213-03-2.48-63
}

Sumário: 1 Introdução; 2 O Brasil da desigualdade: crianças, adolescentes e a pandemia; 3 Fraternidade como imperativo protetivo social na pandemia; 4 Crianças, adolescentes e proteção integral social; 4.1 Políticas de proteção social no Brasil da proteção integral potencializadas fraternalmente; 5 Conclusão; Referências.

\section{Introdução}

O objeto do presente artigo é a potencialidade da Fraternidade no enfrentamento das fragilidades infantoadolescentes aprofundadas pela ocorrência da Pandemia de 2020 no Brasil, pela disseminação do Novo Coronavírus.

A Pandemia do novo Coronavírus em 2020, no Brasil, pôs em evidência características do sistema político, social e econômico do país. Dentre elas, o recorte doloroso da imensa porção da sociedade que já se encontrava vulnerabilizada econômica e socialmente e que, no caso de uma crise sanitária descontrolada, é atingida de forma atroz. Em meio a essa porção da sociedade, figuram crianças e adolescentes: mais frágeis por natureza, tem somado a essa fragilidade, um processo histórico marcado por sua invisibilidade e coisificação.

A resposta política, jurídica e social oferecida à histórica fragilização e desproteção de crianças e adolescentes no Brasil foi inaugurada marcadamente na Constituição da República Federativa do Brasil de 1988 (CRFB/1988) e, em seguida, pela Lei 8.069 de 1990, o Estatuto da Criança e do Adolescente (Estatuto/1990) por meio da Proteção Integral, doutrina jurídica e paradigma em consolidação que reconhece a condição de sujeito de direitos em condição peculiar de desenvolvimento das pessoas com idade até 18 anos, além do princípio da prioridade absoluta na proteção pelo Estado Brasileiro.

A Pandemia do novo Coronavírus de 2020 coloca as instituições brasileiras em xeque no que diz com o cumprimento dos compromissos com a infância, a adolescência e suas famílias. Se, de um lado, todas as pessoas com menos de 18 anos devem receber atenção integral

\footnotetext{
${ }^{1}$ Doutora pelo Programa da Pós Graduação em Direito (PPGD) da Universidade Federal de Santa Catarina (UFSC). Currículo na Plataforma Lattes: http://lattes.cnpq.br/5350520951842278
} 
em sua integridade, mais ainda aquelas que já vivenciam déficit de proteção social: saúde, educação e assistência social são um trunfo constitucional em favor da dignidade das populações vulnerabilizadas econômica e socialmente.

A Fraternidade como valor iluminista, e portanto humanista, por vezes esquecido na cultura ocidental, já vem sendo alvo de pesquisas reflexivas e de aplicação, no Brasil, pelas mãos de juristas, no decorrer da segunda década do século XXI.

Nessa linha, a pergunta-problema que se coloca: em que medida o Princípio da Fraternidade pode funcionar como um potencializador da Proteção Integral de crianças e adolescentes e suas famílias no Brasil pós Pandemia de 2020? Para tanto, investigar-se-á o sentido reconhecido à Fraternidade como Princípio pela doutrina jurídica brasileira e sua potência no enfrentamento das fragilidades infantoadolescentes aprofundadas e mais urgentes em tempos de calamidade pública, a Pandemia do Novo Coronavírus.

Em primeiro quadro, serão levantados os dados da desigualdade estrutural do Brasil relativos às duas primeiras décadas do século XXI, compondo com os dados disponíveis da Pandemia do Coronavírus de 2020. Nessa mesma linha, a condição de vulnerabilização histórica infantoadolescente será explicitada.

Em seguida, pretende-se sistematizar os sentidos atribuídos à Fraternidade no contexto da sociedade ocidental, em geral, e na brasileira em particular.

Em seguida, será respondida a questão acerca da relação de maximização da Doutrina da Proteção Integral infantoadolescente por meio da Fraternidade na cidadania concreta desses sujeitos no período pós Pandemia no Brasil.

A pesquisa bibliográfica aqui utilizada terá como fontes principais, as pesquisas do Núcleos de Estudos Jurídicos e Sociais do Centro de Ciências Jurídicas da Universidade Federal de Santa Catarina (NEJUSCA/CCJ/UFSC) e do Grupo de Pesquisa Direito e Fraternidade do Programa de Pós-Graduação em Direito da Universidade Federal de Santa Catarina (PPGD/UFSC), fruto da atuação das Professoras Doutoras Josiane Rose Petry Veronese e Olga Maria Boschi Aguiar de Oliveira.

\section{O Brasil da desigualdade: crianças, adolescentes e a pandemia.}

Expor as condições em que estão inseridas crianças e adolescentes é sempre situar social e economicamente suas famílias. As famílias brasileiras são marcadas pela chaga da desigualdade estrutural e essa não é uma marca contemporânea, mas remonta à própria construção processual da Sociedade e do Estado brasileiros. 
Fato é que pensar crianças, adolescentes e suas famílias em contexto de Pandemia no século XXI, é lembrar que a existência é extremamente dificultada para uma porção muito grande dessa população e as condições de acesso à saúde, educação, alimentação são diretamente ligadas a essa dificuldade presente na profunda desigualdade e concentração de riqueza e renda.

Tomando como referência a primeira década desse século, a pesquisa financiada pelo Instituto de Estudos Socioeconômicos (INESC), Perfil da Desigualdade e da Injustiça Tributária com Base nos Declarantes do Imposto de Renda no Brasil 2007-2013, traz dados detalhados sobre concentração e desigualdade de renda no país. Percebe-se que mesmo tendo havido a queda da desigualdade no país no período, tendo em vista o coeficiente de Gini, os dados de 2013 do Relatório do PNAD revelam que o Brasil tem a $12^{\mathrm{a}}$ pior concentração de renda no mundo. (SALVADOR, 2016, p. 16)

Sobre o coeficiente de Gini, é de se esclarecer que foi criado pelo matemático e estatístico italiano Corrado Gini e publicado em 1912, consistindo em "[...] em um número entre 0 e 1 , em que 0 corresponde à completa igualdade de renda e 1 , à completa desigualdade. $\mathrm{O}$ índice de Gini é o 186 coeficiente expresso em pontos percentuais" (SOLIGO, 2012, p. 21).

Segundo Soares (2010, p. 377), uma análise dos indicadores obtidos pela Pesquisa Nacional de Amostras por Domicílios (PNAD) de 2001 a 2006 apontava para uma redução da desigualdade de 0,7 ao ano no coeficiente de Gini. Comparativamente com outros países do centro, como EUA e Canadá, e latino-americanos da periferia, o México, o Brasil do fim da primeira década do século XX poderia chegar aos números dos EUA até 2018 reconhecidamente o país mais desigual dentre os centrais no capitalismo mundial, e aos números bastante satisfatórios de desigualdade do Canadá em 2030.

Ainda assim, é interessante relevar que o coeficiente de Gini é um indicador que "[...] reflete a desigualdade relativa da distribuição interpessoal da renda, sendo, portanto, um indicador limitado para uma abordagem mais ampla da desigualdade social ou socioeconômica" (SALVADOR, 2016, p. 16). Há motivos práticos, contudo, para se utilizar um indicador como esse: trata-se de uma opção metodológica que tem sido bem aceita e aplicada no Brasil e vários países, o que facilita a difícil tarefa da comparação (SOARES, 2010, p. 366).

Os dados das declarações de Imposto de Renda no país (IR), sem considerar a sonegação, característica do funcionamento do capitalismo mundial, levam à conclusão de que é escandalosa a concentração de riqueza no Brasil. Os dados da Receita Federal revelam a gravidade da questão a ser enfrentada, pois do montante de $\mathrm{R}$ \$,8 trilhões de patrimônio informados ao Fisco (não se considera aqui a sonegação), em 2013, 41,56\% eram de 
propriedade de apenas 726.725 pessoas, com rendimentos acima de 40 salários mínimos. Isto é, $0,36 \%$ da população brasileira detém um patrimônio equivalente a 45,54\% do PIB do Brasil e com baixíssima tributação. Considera-se, ainda, que essa concentração de renda e patrimônio está praticamente em cinco estados da federação: SP, RJ, MG, RS e PR, agravando ainda mais as desigualdades regionais do país. (SALVADOR, 2016, p. 42)

A desigualdade estrutural no Brasil guarda relação, nos termos de Ribeiro, com a persistência de uma elite associada a interesses capitalistas de centro: "Nada é mais continuado, tampouco é tão permanente, ao longo desses cinco séculos, do que essa classe dirigente exógena e infiel a seu povo. No afã de gastar gentes e matas, bichos e coisas para lucrar [...]" (RIBEIRO, 2013, p. 68).

Como se não bastasse a estrutura acima exposta, as circunstâncias da segunda década do século XXI no Brasil - sem exclusão da conjuntura mundial - levaram a um quadro nada animador no enfrentamento e superação do quadro da desigualdade e concentração de renda.

Um estudo da Fundação Getúlio Vargas (FGV) publicado no ano de 2019 apontou que a desigualdade de renda está crescendo no Brasil, tendo registrado aumento persistente no segundo semestre de 2019, superando o pico histórico observado em 1989. O índice de Gini apresenta uma tendência ascendente após o último trimestre de 2014 no Brasil. Com oscilação para baixo apenas nesse trimestre, segue em viés de alta até o segundo semestre de 2019 (índice de Gini trabalhista aumentou 0,0287). (NERI, 2019, p. 3)

É similar ao ritmo de redução de desigualdade entre 2001 e 2014 (gráfico 13), nesse ponto tivemos o melhor índice da série histórica: 0,6003. A confirmação aparece na elevação em 17 trimestres consecutivos:

"[...] quatro anos de aumento consecutivo de desigualdade, o que constitui um recorde de duração nas séries históricas brasileiras. Nem mesmo em 1989, que constitui o nosso pico histórico de desigualdade brasileira houve um movimento de concentração de renda por tantos períodos consecutivos." (NERI, 2019, p. 3)

Detalhando um pouco mais: pela análise por faixas de renda, a metade mais pobre do país, teve variação para baixo em 17,1\% desde 2014 no Brasil, enquanto $40 \%$ da população uma classe média em termos estatísticos, teve perdas de $4,16 \%$, os $10 \%$ que possuem uma linha de classe média mais aproximada aos padrões estadunidenses, apresentou ganhos de $2,55 \% \mathrm{em}$ sua renda. Dentre todos esses, o $1 \%$ mais rico teve ganhos de $10,11 \%$. Segundo o pesquisador Marcelo Neri (2019, p. 4): "Este seleto grupo tem ocupado lugar de destaque nas discussões distributivas no mundo e no Brasil". 
O aumento da pobreza é mais um indicador certeiro na configuração da vida concreta de crianças, adolescentes e suas famílias no Brasil. Tomando-se a referência de agosto de 2018 da FGV, que corresponde a 233 reais mês por pessoa, detalha-se:

\begin{abstract}
Apenas em 2015, a pobreza subiu 19,3\%, com cerca de 3,6 milhões de novos pobres. [...]. Nossos cálculos revelam que desde o final de 2014 até final de 2017, o aumento de pobreza foi de $33 \%$ [...]. Este contingente representa 23,3 milhões de pobres no país [...]. Ele é resultado da adição de 6,27 milhões de pobres às estatísticas sociais. (NERI, 2019, p. 15)
\end{abstract}

Nesse estado agravado de condições de distribuição e concentração de renda, a população brasileira e suas crianças e adolescentes adentraram em cenário de crise sanitária e econômica no ano de 2020, na Pandemia do chamado Novo Coronavírus.

A análise da gestão política da Pandemia no Brasil de 2020 não é uma possibilidade no âmbito desse trabalho, mas os números oficiais dão o tom: são 55.961 óbitos acumulados e confirmados até 26 de junho de 2020, com um total de 1.274 .974 casos confirmados de contaminação, afora a subnotificação comum e esperada nessas circunstâncias. (BRASIL, 2020, s/p). E a medicina em busca de mais dados para tratamento, cura e protocolos para os efeitos da contaminação no organismo dos recuperados. Na economia, as projeções são de queda vertiginosa do que já não estava em seu melhor momento: o Fundo Monetário Internacional, na projeção de junho de 2020, avalia em queda de 9,1\% na economia brasileira no ano (FUNDO MONETÁRIO INTERNACIONAL 2020, s/p).

É possível inferir a fragilidade de crianças e adolescentes brasileiros, tendo suas famílias sujeitas às mortes, implicações na saúde dos recuperados e na queda dos postos de trabalho, aumento plenamente possível das mais variadas manifestações da violência. Nesse contexto, uma posição já fragilizada pela condição de desenvolvimento, pela dificuldade histórica de lhes retirar a invisibilidade e de lhes enfrentar a "coisificação"2, surge como um desafio para o país.

Os dados são de educação mantida de forma remota, um número considerável de crianças e adolescentes de classes populares com acesso precário à internet ou sem nenhum:

\footnotetext{
A quarentena evidenciou um problema antigo de desigualdade no sistema escolar brasileiro, uma vez que o acesso a internet não é realidade nas casas de muitos estudantes. Em todo o Brasil, 4,8 milhões de crianças não têm acesso a internet - o que equivale a $17 \%$ de estudantes entre 9 e 17 anos, de acordo com a pesquisa TIC Kids Online 2019. (AGÊNCIA BRASIL, 2020, s/p)
}

\footnotetext{
${ }^{2}$ A invisibilidade de crianças e adolescentes e sua "coisificação" (negação do reconhecimento da condição de sujeitos de direitos) são largamente explicitados pela doutrina jurídica no Brasil e apontados pelas ciências humanas e sociais, em geral. Esse tema foi aprofundado e poder ser consultado: ESPEZIM DOS SANTOS, Danielle M; VERONESE, Josiane R. P. A Proteção Integral e o enfrentamento de vulnerabilidades infantoadolescentes. Revista de Direito. Viçosa, v.10 n.02 2018 p. 109-157. [on line]. Disponível em https://periodicos.ufv.br/revistadir/article/view/2056/pdf?fbclid=IwAR0ax0oFrO21CimFpAWCLyCy8kqRsBRlwa5EOQIixJWFDYlhD9E26BwUtw. Acesso em 29jun2020.
} 
Ademais, famílias sem conseguir manter alimentação por perda de poder aquisitivo. Agravada a questão alimentar por falta de acesso à merenda. Muitas famílias indo às ruas - sem proteção e informação suficientes - a fim de obter seu sustento. O risco de aumento dos números de crianças e adolescentes trabalhando precocemente, o que chamamos genericamente de trabalho infantil (UNICEF, 2020, s/p).

Os governos municipais, estaduais e federal informando publicamente auxílios nas diferentes frentes, mas com dificuldades técnicas. As notícias são muitas e a sociedade acompanha, além de mobilizar recursos por meio de doações para as classes mais vulnerabilizadas pelo sistema econômico historicamente desigual e violento.

Nessa linha, ações como a da Fundação Oswaldo Cruz (FIOCRUZ), que construiu uma cartilha bastante valiosa perante as especificidades da população infantoadolescente brasileira, tendo em vista a questão sanitária e a marca da desigualdade:

A pandemia causada pelo novo coronavírus (COVID-19) tem trazido mudanças na
vida cotidiana das crianças. Há indícios de que a taxa de mortalidade nessa faixa etária
é relativamente menor em comparação a outros grupos, como adultos e idosos. No
entanto, é preciso afirmar que todas as crianças estão suscetíveis às repercussões
psicossociais da pandemia. A desigualdade social também determina diferentes níveis
e condições de vulnerabilidade sobre a experiência da infância, de modo que os
profissionais da saúde devem estar atentos às demandas de atenção e cuidado que se
produzem nessa situação. (FIOCRUZ, 2020, p.1)

A história de crianças e adolescentes no Brasil carrega a marca da negação da condição de sujeito, da idealização ou supressão de sua infância, da instrumentalização de sua força e de seu corpo. É sempre necessário atentar, tendo em vista esses elementos, às especificidades de classe, de cor, de gênero, de arranjos familiares e territoriais, reconhecendo fontes próximas às suas experiências e condições de vida.

A Doutrina da Proteção Integral é a resposta político-jurídica a essa condição marcada na história da infantoadolescência brasileira construída na virada de década de 1980/1990, por meio da Constituição da República Federativa do Brasil de 1988 (CRFB/1988) e do Estatuto da Criança e do Adolescente de 1990 (Estatuto/1990). Reconheceu-se ao Estado brasileiro o compromisso de garantir dignidade concreta a crianças e adolescentes por meio de um conjunto de princípios humanistas; direitos fundamentais de liberdade e sociais, individuais e coletivos; garantias de cunho material, processual e institucional. Um verdadeiro sistema de garantias de direitos assumido por um país que jamais repartiu e que reconheceu-se devedor diante da fragilidade e da esperança de suas crianças. 


\section{Fraternidade como imperativo protetivo social na pandemia}

A Fraternidade é valor declarado do ideário iluminista original, como consta do lema da Revolução Francesa - Liberdade, Igualdade e Fraternidade. Nesse sentido, trata-se de imperativo reconhecido no discurso ocidental, mas relegado a um lugar menos prestigiado, posto que os dois primeiros passaram a compor dimensões de direitos humanos, acolhidos por tratados internacionais e Constituições dos Estados-Nação. Justamente na linha da reflexão acerca do "esquecimento" da Fraternidade, afirma Baggio (2009, p. 18), que "[...] a problemática realização da liberdade e da igualdade, inclusive nos países democráticos mais desenvolvidos, não poderia ser devida justamente ao fato de a ideia da fraternidade ter sido quase que totalmente abandonada?”. (BAGGIO, 2008, p. 18)

As ideias e as práticas relativas à Fraternidade têm relação com o período antecedente à Revolução Francesa, na doutrina cristã, antecedendo Liberdade e Igualdade, sendo afastadas justamente por essa ligação com o termo "irmão" e por serem opostas à perspectiva da ambição humana, base da sociedade que se estabeleceu no pós revolução. (BAGGIO, 2009, P. 9).

O ambiente jurídico-político necessário a uma sociedade atravessada por desigualdade estrutural e avassalada pela Pandemia de 2020 do Coronavírus, como a brasileira, demanda retomada da Fraternidade como imperativo, valor, ou seja, princípio fundamental implícito no ideário constitucional.

Nichnich (2016, p. 152) salienta a importância de se resgatar a Fraternidade no âmbito constitucional do Direito do Estado Democrático de Direito, posto que sustentaria, na “[...] reafirmação dos valores abarcados pela liberdade e pela igualdade, o fomento de práticas jurídicas inclusivistas e a contribuição para a realização da dignidade humana.” Para essa jurista: “[...] viver em democracia implica em solidificar espaços de reconhecimento de si e do "outro". Para tanto, a fraternidade ainda está em construção como categoria jurídica." (NICHNICH, 2016, p. 154).

A cultura ocidental demanda revisão e o Direito, enquanto linguagem do Estado Democrático na relação com a Sociedade que o sustenta e o legitima, deve assumir como via de resposta, a reincorporação da Fraternidade como valor orientador de sua atividade hermenêutica. Pois em uma fase histórica como a que se mira, os instrumentais utilizados em tempos de calmaria não poderão dar respostas, a não ser que potencializados em sua vocação mais legítima: reconhecimento do "outro" mais frágil.

Nesse ponto, na linha do reconhecimento do "outro", reside o reconhecimento das necessidades materiais de crianças, adolescentes brasileiros e suas famílias. Essa linha de 
reconhecimento encontra no Sistema de Garantias e Direitos infantoadolescentes, um lugar denso e estruturado, que são os direitos fundamentais sociais.

\section{Crianças, adolescentes e proteção integral social}

Quanto à proteção social de crianças, adolescentes e suas famílias, há um rol de direitos extremamente denso já na formulação original do texto constitucional (Art. 227, caput, CRFB/1988) e estatutário (Art. $4^{\circ}$, caput, Estatuto): vida, saúde, liberdade, respeito, dignidade, convivência familiar e comunitária, educação, cultura, esporte, lazer, profissionalização e proteção no trabalho.

Afinando o olhar, a CRFB/1988, por meio do artigo $6^{\circ}$ devidamente cruzado com o artigo 203 da mesma norma, alça a assistência social a direito fundamental de crianças e adolescentes, tanto por sua condição vulnerável intrínseca, quanto em hipóteses de vulnerabilidade econômica ou social:

\footnotetext{
"A assistência social será prestada a quem dela necessitar, independentemente de contribuição à seguridade social, e tem por objetivos: I - a proteção à família, à maternidade, à infância, à adolescência e à velhice; II - o amparo às crianças e adolescentes carentes; [...]".
}

Separar, no rol de direitos fundamentais infantoadolescentes, aqueles que podem ser classificados como direitos socais e, por fim, concorrer para a proteção social dessa população não é tarefa simples. Está claro, porém, que todos os direitos apontados acima - à exceção da liberdade (art. 16, Estatuto) — são ligados à tradição social — de segunda dimensão — e são, preponderantemente prestacionais. Ou seja, enquadram-se como pretensos direitos (subjetivos) fundamentais de crianças e adolescentes de cunho prestacional material perante o Estado: vida, saúde, dignidade, respeito, convivência familiar e comunitária, educação, cultura, esporte, lazer, profissionalização, proteção no trabalho e assistência social.

Saliente-se, em primeiro lugar, que a pretensão subjetiva prestacional (dos direitos de tradição social) existe sempre, em tese, mesmo em uma perspectiva dogmática mais restritiva (MENDES e BRANCO, 2015; SILVA, 2012), tendo em vista a aplicabilidade ou eficácia jurídica intrínseca a todos os direitos declarados constitucionalmente; o que se necessita é sempre analisar a positivação mais atentamente, no caso peculiar dos direitos sociais prestacionais, para atestar o grau de densidade normativa e a consequente exigibilidade.

Em segundo lugar, há uma necessária abertura no rol de direitos sociais a ser mantida, dada a característica multifacetada dos direitos fundamentais, em geral, e também para o sujeito criança/adolescente. Sobre essa característica multifacetada e o alerta acerca da abertura do rol 
de direitos sociais, no caso do Estatuto, ilustra-se com o direito à vida (art. $7^{\circ}$ e ss. do Estatuto), tradicionalmente reconhecido como direito de defesa, a exigir respeito de outrem e, na ótica estatutária apresentar também natureza prestacional, posto estar relacionado diretamente aos direitos à saúde, como se verá a seguir. Mais um exemplo que ilustra o argumento na seara estatutária: o direito ao lazer aparece, quando afeto a crianças e adolescentes, ora como direito de defesa — “ Art. 16. O direito à liberdade compreende os seguintes aspectos: [...] IV - brincar, praticar esportes e divertir-se; [...]" — , ora como direito a prestações materiais estatais — “Art 59 . Os municípios, com apoio dos estados e da União, estimularão e facilitarão a destinação de recursos e espaços para programações culturais, esportivas e de lazer voltadas para a infância e a juventude."

É certo que os direitos sociais de crianças e adolescentes - ou seja, a proteção social são centrais em termos de Proteção Integral, em tempos sem Pandemia, quem dirá no agravamento de sua vulnerabilização atravessada pela desigualdade estrutural brasileira.

A contribuição de Sarlet (2009, p. 152) ao debate acerca da configuração dos direitos sociais como direitos subjetivos se dá na sedimentação "[...] de que ao titular de um direito fundamental é aberta a possibilidade de impor judicialmente seus interesses juridicamente tutelados perante o destinatário."

Especificamente sobre as prestações materiais, típicas dos direitos sociais, releva-se que há especificidades no manejo de um tipo de direito para o outro, em termos de grau de exigibilidade e, ainda, no que diz respeito a se dirigirem contra diferentes destinatários (SARLET, 2009, p. 153). Nesse ponto, a teoria desse jurista brasileiro, acresce à tradição da ciência jurídica, pois assume que, com todas as suas peculiaridades, os direitos sociais são tão exigíveis, em tese, quanto os tradicionais direitos de liberdade. O que demanda, na continuação, sempre a análise mais pormenorizada de direito sociais, um a um, com vistas ao julgamento de seu grau de exigibilidade, que "[...] é de intensidade variável e dependente da normatividade de cada direito individual.” (SARLET, 2009, p. 154).

A constatação de que os direitos fundamentais sociais exigem atividade interpretativa peculiar passa, necessariamente, pela distinção entre aplicabilidade/eficácia jurídica e eficácia social. A primeira leva em conta aspectos normativos que gerem a chamada exigibilidade judicial ou justiciabilidade, nos termos adotados por Sarlet (2009, p. 260). Esses aspectos são relacionados ao grau de densidade da norma positivadora dos direitos fundamentais. A segunda, diz respeito à forma como o(s) destinatário(s) da norma, ou obrigado por ela, lhe dá cumprimento no mundo fático; equivale à efetividade. 
Assume-se aqui aplicabilidade e eficácia jurídica como fenômenos aproximados, embora não se possa atestar que uma norma aplicável sempre será aplicada (SARLET, 2009, p. 237). Uma análise profícua em termos do presente estudo, ao menos no que diz respeito à contundência das normas de direitos fundamentais sociais e à construção doutrinária hábil à consecução de dignidade concreta para os sujeitos dos direitos em estudo, é o nível de densidade das normas que os acolhem. Essa espécie de normas (definidoras de direitos sociais em nível constitucional), quando compreendidas como programáticas, se classificam, historicamente, em definidoras de programas, fins e tarefas a serem implementados pelo Estado (SARLET, 2009, p. 281). Porém, análises individualizadas, como dito, podem localizá-las em níveis mais densos quanto ao tipo de objeto, as obrigações decorrentes e os obrigados, além das garantias relativas aos bens visados, pois todas as normas - em nível constitucional - elas podem ser mais ou menos densas e, assim, enquadrarem-se em normas constitucionais de eficácia plena ou normas constitucionais de eficácia limitada ou reduzida. (SARLET, 2009, p. 253).

O conceito, a função e o sentido assumido acerca dos direitos fundamentais sociais são importantes fatores na definição de seu potencial de enfrentamento à desigualdade estrutural, além da proteção social em tempos de vulnerabilização extrema, como é o caso da Pandemia pelo coronavírus de 2020 .

De uma forma ou de outra, se não se reconhecer que as normas de direitos sociais geram direitos subjetivos, segue-se em uma teoria pouco profícua em termos de efetiva concretização de igualdade, principalmente em países com grandes diferenças de patamares — social e econômico — de acesso à dignidade concreta. Se desse reconhecimento não advier a análise de sua aplicabilidade pela via do grau de densidade normativa assumida pela norma positivadora, também se reduz o potencial garantista e, muito mais ainda, seu potencial concretizador de uma dignidade concreta.

Bonavides (2012, p. 608-609) insiste em localizar, em países periféricos como os latinoamericanos, a concretização de um Estado Social como a única maneira de se garantir legitimidade e democracia e, consequentemente, paz e soberania. Acrescenta Bonavides (2012, p. 608) que os ataques existentes aos direitos sociais buscam enfraquecer sua exigibilidade e, enquanto não logram esse desiderato, buscam mantê-los instáveis, debaixo da ameaça de revogação, ou — como se isto já fora possível — fazê-los retroceder vazios às esferas programáticas da Constituição, ao tempo que permaneceram relegados ao esquecimento e abandono na época clássica do constitucionalismo liberal.

Bastante clara a relação entre Fraternidade e direitos fundamentais sociais, nos estudos de Nichnich (2016, p.158): 
Vislumbra-se o comprometimento para com tais normas, que advém por meio da fraternidade. O direito à educação direciona - se a sua efetividade à luz da fraternidade, quando, por exemplo, se verifica o comprometimento do Estado (fraternidade estatal) e dos operadores educacionais (fraternidade individual - aplicação do princípio da eficácia horizontal da fraternidade) no sentido de capacitar o educando, oriundo de escolas públicas, a concorrer no mercado de trabalho, em concursos e em ingressos em universidades em igualdade ao proveniente de escola particular. Não há educação sem fraternidade.

Justamente nessa linha, a contradição apontada por Nichnich: "[...] questiona-se qual o significado da liberdade e da dignidade se desconectadas do princípio da fraternidade. Ambas possuiriam significados que não ultrapassariam a fronteira do simbólico, conforme já exposto." (2016, p. 159) [sem grifo no original]. E assim, diante das promessas iluministas mais prestigiadas no pós revoluções, liberdade e igualdade, é bastante plausível e razoável que se evoque a Fraternidade afirmando que ela:

[...] não permite que o indivíduo fique indefeso ao legalismo exacerbado, às instituições governamentais ou às leis do mercado. Impede, inclusive, a tendência de seres humanos voltados ao bem-estar material, com capacidade acrítica e participação política reduzida, abrindo espaço aos regimes totalitários. (NICHNICH, p. 159)

$\mathrm{Na}$ disputa entre dois extremos dos valores iluministas - individualidade e coletividade - deve operar e ponderar a Fraternidade. Veja-se o que já existe em termos de ferramentas políticas e normativas no caminho da proteção social de crianças e adolescentes a serem potencializadas fraternalmente.

\subsection{Políticas de proteção social no Brasil da proteção integral potencializadas fraternalmente}

As previsões de proteção social para crianças e adolescentes no Brasil passam pela Proteção Integral como doutrina jurídica, sim, mas por opções políticas fraternas calcadas no texto constitucional e no Estatuto que desnudam a vocação contundente dessas políticas.

No desenho normativo relativo à Proteção Integral Social, dois caminhos se evidenciam para o enfrentamento da desigualdade econômico-social no Brasil da pobreza (vulnerabilidade econômica) e da vulnerabilidade etária (sujeito em condição peculiar de pessoa em desenvolvimento). Um é a diretriz da participação social por meio de conselhos de direitos nos níveis municipal, estadual e nacional - CRFB/1988, art. 227, $\S 7^{\circ} \mathrm{c} / \mathrm{c}$ art. 204, II e Estatuto, artigo 88, II - e o outro se refere ao viés participativo de outras políticas sociais no país, bem ilustradas pelas opções constitucionais e infraconstitucionais referentes às políticas de educação e assistência social. 
De modo geral, as políticas públicas sociais infantoadolescentes são ações esperadas a partir da decisão constitucional e estatutária de proteger integral e prioritariamente essa camada da população. Assim consideradas, a zona de discricionariedade administrativa - o juízo de oportunidade e conveniência da administração pública - reduz ao "como fazer" e ao "como gastar" o orçamento público.

Nesse sentido, é preciso situar essas exigências no campo das políticas de Estado a fim de frisar que não se pode escolher entre cumprir ou não cumprir as normas de direitos sociais de pessoas em condição peculiar de pessoa em desenvolvimento. Mas se pode escolher como cumpri-las. A definição da linha da discricionariedade se dá pelo desenho normativo - mais ou menos denso - que tais direitos recebem das normas superiores do ordenamento jurídico.

No caso brasileiro, a CRFB/1988, o Estatuto/1990 e outras leis federais que regulam detalhadamente direitos sociais como educação, saúde e assistência social densificam as políticas de Proteção Integral Social.

Trata-se de bens da vida material direcionados para uma população prioritária de forma absoluta, urgente — para escapar dos termos técnico-normativos — "[...] direitos que constituem pressupostos para o funcionamento da deliberação majoritária e sem os quais o controle social das políticas públicas dissipa-se no ciclo corrupção-ineficiência-clientelismo [...]”. (BARCELLOS, 2013, p. 132).

A distinção entre políticas de governo e políticas de Estado auxilia no enfrentamento das oscilações na proteção da população infantoadolescente, tanto possuem potencial de enfrentamento da ineficiência e da corrupção, quanto do clientelismo, pela via da transparência, participação popular e casamento entre aspectos técnicos e democráticos. É bom relevar que políticas de Estado merecem essa denominação sempre que forem atreladas a decisões das normas superiores vinculadas pelo pacto constitucional vigente e não puderem ser subsumidas por um plano ou políticas de governo, em face do alto grau de densidade normativa que possuem. Nesse campo se inserem as políticas de Proteção Integral Social, tanto mais se referirem a direitos fundamentais com alto grau de densidade normativa.

Exemplificando com os direitos fundamentais à assistência social e o direito à convivência familiar e comunitária: não é deixado à administração pública um campo de discricionariedade tal, que possa optar por não oferecer serviços de proteção social a crianças e adolescentes vítimas de violências dos mais variados tipos e graus, mediante a criação de CRAS - Centros de Referência em Assistência Social, CREAS - Centros de Referência Especializada em Assistência Social — e serviços de acolhimento, seja institucional, seja familiar. Esses últimos serviços, para casos mais graves (artigo 227 c/c 204, CRFB/1988; 
artigos 86, 87, 90, 101, Estatuto/1999; artigos $6^{\circ} \mathrm{A}$, I e II; $6^{\circ} \mathrm{C}$, LOAS; Resolução 109/2009/CNAS).

Na ilustração da convivência familiar e comunitária e da assistência social, conjuga-se a existência de espaços de discussão sobre local e caminhos para a sistematização dos serviços e suas políticas públicas sempre tendo em vista diagnósticos acerca das vulnerabilidades territoriais, com avaliação dos serviços já disponíveis de forma a se manter proteção com democracia, além da transparência e eficiência da máquina pública. Como se vê: "[...] uma concepção na qual as ações administrativas sejam fruto do planejamento ponderado, bem como dotadas de força normativa. [...] mesmo havendo alternância partidária no poder, restaria para os cidadãos a possibilidade de exigir o cumprimento de políticas públicas institucionalizadas" (OHLWEILER, 2013, p. 299-300).

A inserção das políticas de Proteção Integral Social no campo das políticas de Estado tende a municiar a superação de uma doutrina jurídica conservadora de supremacia do interesse público, tomado como vinculação direta entre a vontade da Administração e o denominado bem comum. Na linha do que esclarece Mazzilli (2011, p. 49-50), uma bipartição entre interesse público primário e secundário auxilia na acomodação de eventual choque entre interesse da Administração Pública e interesse da coletividade, entendido como bem comum ou interesse geral: o primeiro trata do interesse público secundário e o segundo, interesse público primário. Lembrar que o interesse público primário é sempre uma decisão que não repousa exclusivamente na vontade da administração pública, mas em uma conjugação de vontades inscritas na norma e na participação popular, o que possibilita maior transparência e legitimidade para a concretização da Proteção Integral Social.

O passo que se pode e se deve dar na interpretação e aplicação do Direito, em geral, e no Direito da Criança e do Adolescente com sua Doutrina da Proteção Integral, em particular, em tempos nada regulares de funcionamento da sociedade brasileira, é assumir a Fraternidade como substrato da proteção social, compreendendo os direitos sociais reconhecidos na CRFB/1988 e no Estatuto/1990 como obrigações públicas, como políticas de Estado e não de governos.

\section{Conclusão}

O presente trabalho se voltou para a potencialidade da Fraternidade no enfrentamento das fragilidades infantoadolescentes aprofundadas pela ocorrência da Pandemia de 2020 no Brasil, pela disseminação do Novo Coronavírus. A pergunta-problema investigada: em que 
medida o Princípio da Fraternidade pode funcionar como um potencializador da Proteção Integral de crianças e adolescentes e suas famílias no Brasil pós Pandemia de 2020?

O caminho trilhado levantou o aprofundamento das fragilidades de crianças, adolescentes e famílias no contexto brasileiro no período anterior à ocorrência da Pandemia pela disseminação do Coronavírus de 2020 no país e na sua efetiva deflagração. O quadro obtido pelo cruzamento das pesquisas bibliográficas acerca da infantoadolescência - e suas famílias com as estatísticas relacionadas à desigualdade estrutural - com profunda concentração de renda e riqueza - no país demonstrou a necessidade de se priorizar a proteção social.

A investigação acerca dos sentidos e da potência da Fraternidade, evidenciou seu reconhecimento como valor, princípio reconhecidamente presente na cultura ocidental pré e pós iluminismo, porém com prestígio negado pela sociedade pós revoluções: um indicativo contundente do quanto a retomada política e jurídica da Fraternidade seria uma possibilidade para essa mesma cultura, tanto reconhecer a tendência desviante da exacerbação exclusiva da Liberdade ou da Igualdade, quanto conferir o lugar devido ao reconhecimento do "outro".

Fraternidade como imperativo do reconhecimento do "outro" que, no recorte dessa pesquisa, assume a feição de crianças e adolescentes brasileiros, com suas especificidades, com sua voz, com sua cor, com seu gênero, com seus arranjos familiares e comunitários sempre servindo de parâmetros na aplicação da lei e nas decisões políticas.

A Proteção Integral como doutrina jurídica, devidamente reconhecida, ao ser recortada para a seara da Proteção Social, pode e deve - por obrigação constitucional e de ética pública encontrar a Fraternidade como potencializadora desse reconhecimento de crianças, adolescentes e famílias fragilizadas historicamente e profundamente abaladas em suas vidas cotidianas e em sua cidadania em meio a um contexto de Pandemia.

O âmbito jurídico e político da Sociedade brasileira deverá se abrir às demandas da Proteção Integral no cumprimento das obrigações decorrentes dos bens sociais, tanto na elaboração, reordenamento e ampliação das políticas públicas e de orçamento, quanto no controle judicial restrito à normatividade constitucional e infraconstitucional.

Nessa linha, a potencialidade foi demarcada aqui e demanda outros estudos de natureza bibliográfica, documental e estatística, já que se vislumbra uma verdadeira mudança de época no período ora estudado. Nesses tempos, muitas mudanças estão ocorrendo e ainda ocorrerão. Se mudanças reafirmarão os compromissos da cultura ocidental humanista com a Fraternidade, só a observação atenta dirá. 


\section{REFERÊNCIAS}

AGENNCIA BRASIL. Caminhos da reportagem aborda rotina das crianças durante a Pandemia. Public.: 30mai2020. Disponível em

https://agenciabrasil.ebc.com.br/esportes/noticia/2020-05/caminhos-da-reportagem-abordarotina-das-criancas-durante-pandemia. Acesso em 27jun2020.

BAGGIO, Antonio Maria. A Fraternidade na reflexão atual das ciências políticas. In:

BAGGiO, Antonio Maria. O Princípio Esquecido. vol. 1. São Paulo: Cidade nova, 2008.

BAGGIO, Antonio Maria. Fraternidade e reflexão politológica

contemporânea. In BAGGIO, Antonio Maria (Org.). O princípio esquecido: exigências, recursos e definições da fraternidade na política. Vargem Grande Paulista, (SP): Cidade Nova, 2009, v. 2.

BARCELLOS, Ana Paula. Constitucionalização das políticas públicas em matéria de direitos fundamentais: o controle políticosocial e o controle jurídico no espaço democrático. In: SARLET, Ingo Wolfgang; TIMM, Lucino Benetti. (Org.) Direitos fundamentais: orçamento e reserva do possível. 2 ed. Porto Alegre: Livraria do Advogado, 2013, pp. 101132.

BONAVIDES, Paulo. Curso de direito constitucional. 27. ed. atualiz. São Paulo: Malheiros, 2012.

BRASIL. 2009b. Resolução no 109, de 11 de novembro de 2009. Conselho Nacional de Assistência Social. Aprova a Tipificação Nacional de Serviços Socioassistenciais.

Reimpressão 2014. Disponível em https://www.mds.gov.br/webarquivos/public/resolucao_CNAS_N109_\%202009.pdf. Acesso em 27jun2020.

BRASIL. Ministério da Saúde. COVID19: Painel Coronavírus. Atualiz.: 26/06/2020, 19:00. Disponível em https://covid.saude.gov.br/. Acesso em 27jun2020.

ESPEZIM DOS SANTOS, Danielle M. A luta por direitos infantoadolescentes no Brasil: Doutrina da Proteção Integral e o direito fundamental à assistência social. In: VERONESE, Josiane Rose Petry; SILVA, Rosane Leal da (Orgs.). A Criança e seus Direitos: entre violações e desafios [recurso eletrônico]. Porto Alegre, RS: Editora Fi, 2019. Disponível em https://3c290742-53df-4d6f-b12f-

6b135a606bc7.filesusr.com/ugd/48d206_821879e0e1924fed9a41cf6e965b4703.pdf. Acesso em 29jun2020.

FIOCRUZ . Fundação Oswaldo Cruz. Crianças na Pandemia Covid-19: - Você pode muito. Com informação, pode ainda mais. 2020. Disponível em https://www.fiocruzbrasilia.fiocruz.br/wpcontent/uploads/2020/05/crianc\%cc\%a7as_pandemia.pdf. Acesso em 27jun2020.

FUNDO MONETÁRIO INTERNACIONAL. FMI. Reopening from the Great Lockdown: Uneven and Uncertain Recovery. Public.: 24/06/2020. Disponível em https://blogs.imf.org/2020/06/24/reopening-from-the-great-lockdown-uneven-and-uncertainrecovery/. Acesso em 27jun2020. 
MAZZILLI, Hugo Nigro. A defesa dos interesses difusos em juízo. 24 ed. rev. ampl. e atualiz. São Paulo: Saraiva, 2011.

MENDES, Gilmar Ferreira; BRANCO, Paulo G. Gonet. Curso de Direitos Constitucional. 10. ed. rev. e atualiz. São Paulo: Saraiva, 2015. (Série IDEP).

NERI, Marcelo. A Escala da Desigualdade: qual foi o impacto da crise sobre a distribuição de Renda e a Pobreza? 15 de agosto de 2019. Disponível em https://www.cps.fgv.br/cps/bd/docs/A-Escalada-da-Desigualdade-Marcelo-Neri-FGVSocial.pdf. Acesso em 09jun2020.

NICKNICH, Mônica. A Fraternidade e os direitos sociais: reflexões à luz do pensamento de Hannah Arendt. In: VERONESE, Josiane Rose Petry; OLIVEIRA, Olga Maria Boschi Aguiar de; MOTA, Sergio Ricardo Ferreira. (Org.). O Direito revestido de Fraternidade: estudos desenvolvidos no programa de pós-graduação em Direito da UFSC. Florianópolis: Insular, 2016, p. 149-163.

OHLWEILER, Leonel Pires. Políticas públicas e controle jurisdicional: uma análise hermenêutica à luz do Estado Democrático de Direito. In: SARLET, Ingo Wolfgang; TIMM, Lucino Benetti. (Org.) Direitos fundamentais: orçamento e reserva do possível. 2 ed.. Porto Alegre: Livraria do Advogado, 2013, pp. 289-310.

UNICEF. Organização das Nações Unidas (ONU). Trabalho infantil na pandemia pode impedir retorno de crianças à escola. [recurso eletrônico]. Pub. 12/05/2020. Disponível em https://nacoesunidas.org/unicef-trabalho-infantil-na-pandemia-pode-impedir-retorno-decriancas-a-escola/. Acesso em 27jun2020.

RIBEIRO, Darcy. O povo brasileiro: evolução e o sentido do Brasil. 3 ed. São Paulo: Companhia das Letras, 2013.

SALVADOR, Evilasio. Perfil da desigualdade e da injustiça tributária com base nos declarantes do Imposto de Renda no Brasil 2007-2013 [meio eletrônico]. Brasília: Instituto de Estudos Socioeconômicos (INESC), 2016. Disponível em https://www.ceapetce.org.br/uploads/documentos/587e0c439bbf33.59808206.pdf. Acesso em 27 jun2020.

SARLET, Ingo Wolfgang. A eficácia dos direitos fundamentais. 10 ed. rev., atualiz. e ampl. Porto alegre: Livraria do Advogado, 2009.

SOARES, Sergei Suarez Dillon. O ritmo na queda da desigualdade no Brasil é aceitável? Revista de Economia Política. [revista eletrônica]. Vol. 30, no 3 (119), jul/set, 2010, pp. 364380. Disponível em http://dx.doi.org/10.1590/S0101-31572010000300001. Acesso em 27 jun2020.

SOLIGO, Valdecir. Indicadores: conceito e complexidade do mensurar em estudos de fenômenos sociais. Estudos em Avaliação e Educação. [revista eletrônica].Vol. 23, n 52 , São Paulo, mai/ago, 2012, p. 12-25. Disponível em http://www.fcc.org.br/pesquisa/publicacoes/eae/arquivos/1724/1724.pdf. Acesso em 27 jun2020. 